\title{
Comparison of the effect of thiopental sodium-midazolam combination on the hemodynamic response between tracheal intubation and laryngeal mask airway insertion: A clinical trial study
}

\author{
Shetabi $\mathbf{H}^{1}$, Honarmand $\mathrm{A}^{2}$, Adinehmehr $\mathbf{L}^{3}$, Kaviani $\mathbf{R}^{4}$ \\ 1. Assistant Professor of Anesthesiology, Anesthesiology and Critical Care Research Center, Isfahan University \\ of Medical Sciences, Isfahan, Iran. \\ 2. Professor of Anesthesiology, Anesthesiology and Critical Care Research Center, Isfahan University of \\ Medical Sciences, Isfahan, Iran. \\ 3. Assistant Professor of Anesthesiology, Anesthesiology and Critical Care Research Center, Isfahan University \\ of Medical Sciences, Isfahan, Iran (Corresponding Author), Tel: +98-83138222532, Email: \\ liliadineh@yahoo.com \\ 4. Student Research Committee, Faculty of Medicine, Isfahan University of Medical Sciences, Isfahan, Iran.
}

\begin{abstract}
Background and Aim: The purpose of this study was to compare the effect of thiopental sodium-midazolam combination on the stress response and hemodynamic changes between tracheal intubation and laryngeal mask airway insertion during airway management.

Materials and Methods: In this clinical trial study, 70 patients ASA 1, 2 candidates for elective surgery were randomly divided into two groups of tracheal intubation and laryngeal airway mask insertion. Hemodynamic variables including mean arterial pressure, heart rate, and arterial oxygen saturation were measured and compared between the two groups before and after intubation.
\end{abstract}

Results: There was no significant difference between the two groups in regard to demographic data (age, sex, height, and weight), heart rate, mean arterial pressure and arterial oxygen saturation at 1 and 3 minutes after induction of anesthesia and 1, 3,5 and 10 minutes after intubation. $(\mathrm{P}>0.05)$. But there were significant differences between the two groups in relation to heart rate at 1 and 3 minutes after intubation, so that heart rate at these times was significantly higher in the intubation group than in the laryngeal airway mask group ( $\mathrm{P}$ $<0.05)$.

Conclusion: Based on the findings of this study, use of thiopental sodium midazolam combination was effective and safe and attenuated the stress response to airway management with resultant minimal changes in the heart rate and blood pressure.

Keywords: Thiopental sodium, Midazolam, Tracheal intubation, Laryngeal mask airway, Stress response, Hemodynamic changes

Received: Jan 7, $2019 \quad$ Accepted: Mar 16, 2019

How to cite the article: Shetabi H, Honarmand A, Adinehmehr L, Kaviani R. Comparison of the effect of thiopental sodium-midazolam combination on the hemodynamic response between tracheal intubation and laryngeal mask airway insertion: A clinical trial study. SJKU 2019;24(2):99-100. 


\section{مقايسه تأثير تركيب تيوينتال سديم - ميدازولام بر پاسخ هموديناميك به لولهكذارى تراشه و قراردادن ماسك حنجر ماى: يك مطالعه كار آزمايى بالينى}

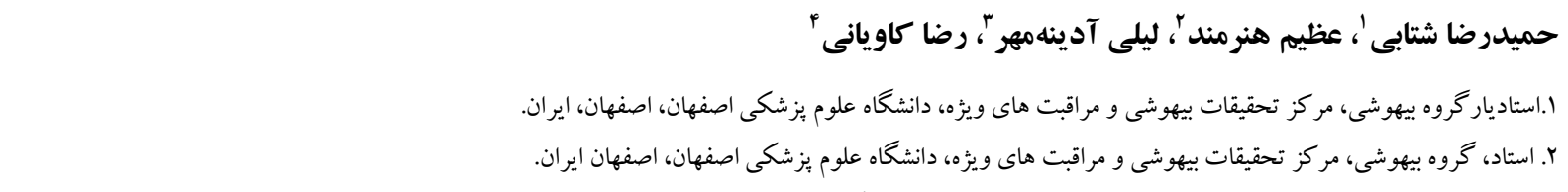

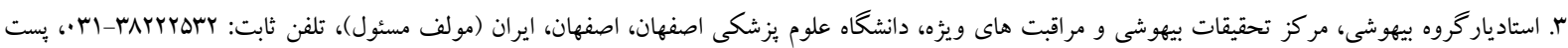

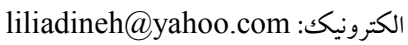
r. كميته تحقيقات دانشجويى، دانشكده يزشكى، دانشكاه علوم يز شكى اصفهان، اصفهان، ايران. جكکيله زمينه و هدف: اين مطالعه با هدف بررسى تأثير تركيب تيوينتال سديم-ميدازولام بر باسخ استرسى و تغييرات هموديناميك حين ادارهى راه هوايى با لوله گذارى تراشه يا ماسك حنجرهاى انجام شد. روش بررسى: در اين مطالعه كارآزمايى بالينى، •V بيمار با ASA اوץ كانديد جراحى الكتيو بهطور تصادفى در دو كروه

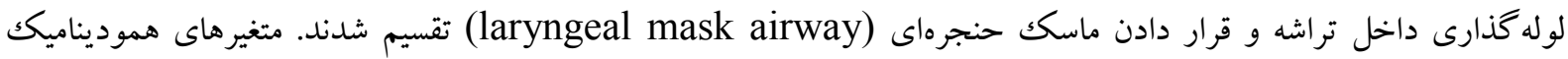

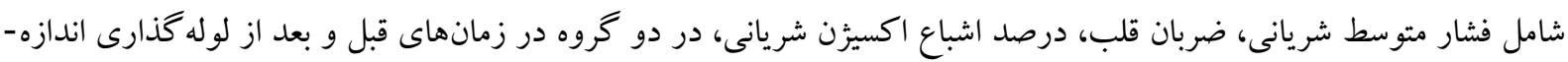
گيرى شد و مورد مقايسه قرار گرفت.

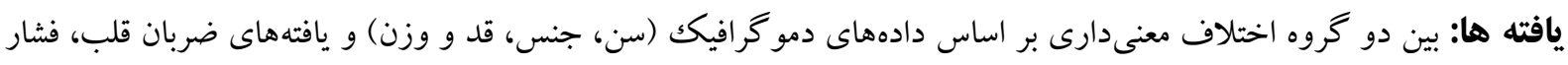

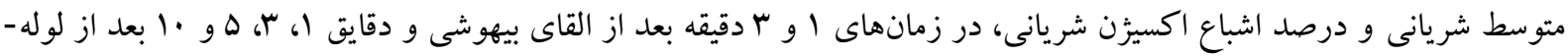

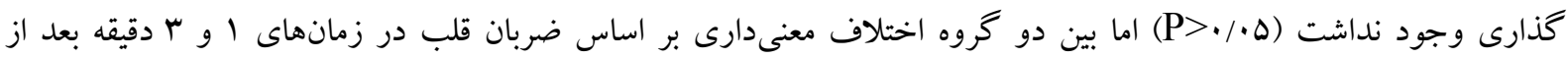

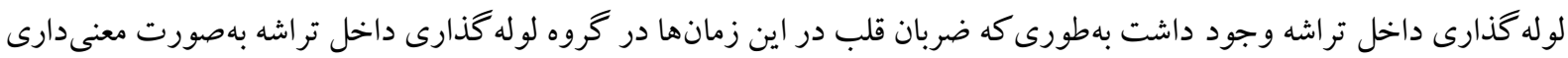

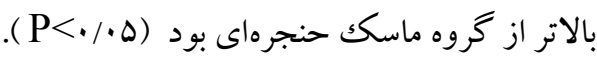

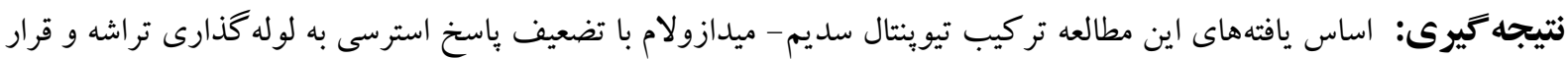
دادن ماسك حنجره و حداقل تغييرات ضربان قلب و فشار خون همراه است و تر كيبى مؤثر و ايمن است.

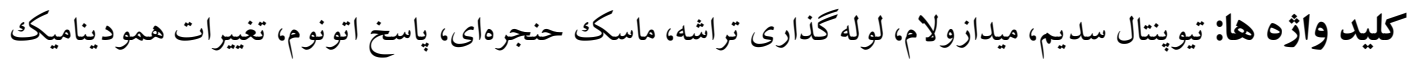

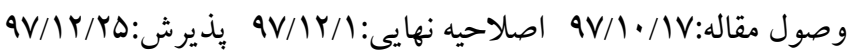


تراشه با نتايج متفاوت استفاده شده است. تمام اين عوامل دارويى مزاياى و معايب خاص خود را داشته و هيجيك تئك بدون عارضه نبودند (Y-A).

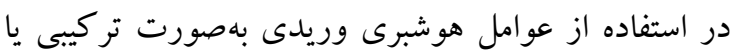
تجويز همزمان، به علت كاهش در دوز هريك از داروها

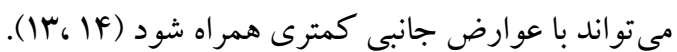
باربيتوراتها بسيارى از اثرات خود را از طريق تقويت مهار

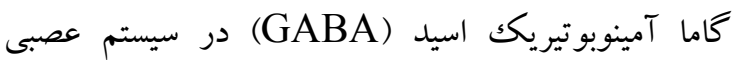

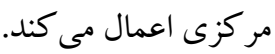
تيوينتال يكك باربيتورات سريع الاثر با طول اثر كوتاه است

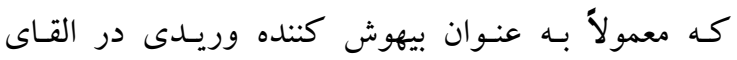

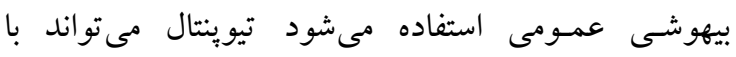

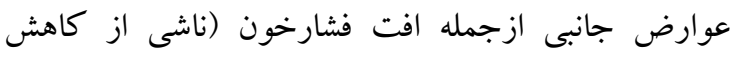

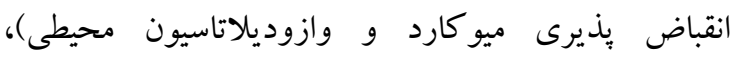

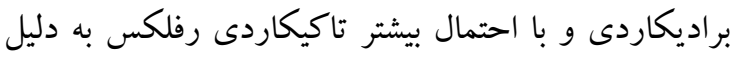

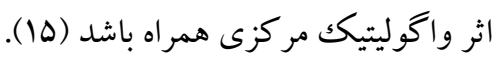

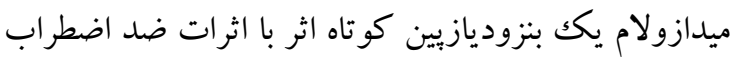
و آرامبخشى است ميدازولام به دليل ايجاد القايى آرام همراه با عوارض قلبى عروقى و ساير عوارض جانبى كمتر

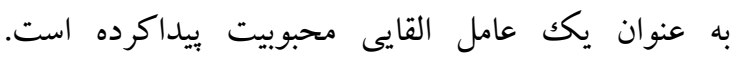

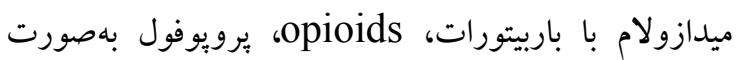

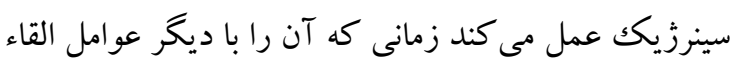

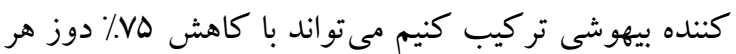
يكك اين عوامل همراه باشد (19).

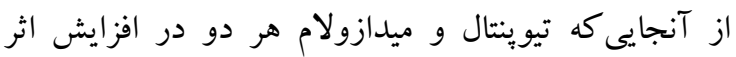
مهارى GABA در سيستم عصبى مركزى نقش دارند، انتظار مىرود در القاى همزمان، اثر سينرزيك داشته و نياز به دوزهاى كمترى از هر كدام باشد (10). با توجه به مطالعات محدود در زمينه تاثيرتر كيب داروهاى بيهوشى بر تضعيف باسخ اتونوم و هموديناميك در اداره راه

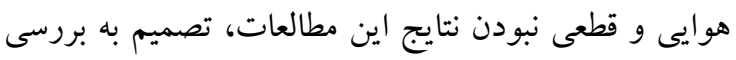

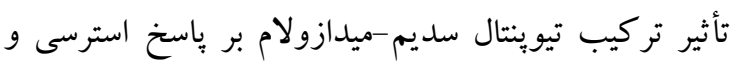

\section{مقدمه}

بايه اصلى در مديريت كافى راه هوايى لارنكوسكويى و لوله كذارى داخل تراشه است كه داراى مزاياى زيادى از جمله ارائه فراهم آوردن راه هو ايى قابل اعتماد، بيشگيرى از

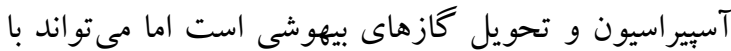
عوارضى مانند آسيب راه هوايى، رفلكسهاى فيزيولوزيك مانند هييوكسى، تاكى كاردى و يرفشارى خون،

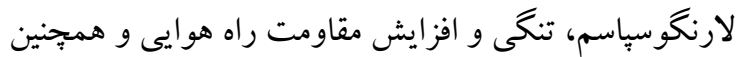
ادم ريوى فشار منفى، در حين و يس از انتوباسيون و در حين اكستيوب (خروج لوله تراشه) همراه باشد (1). ماسك حنجره روشى بسيار كم تهاجمى براى نگگهدارى راه

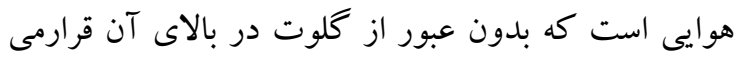

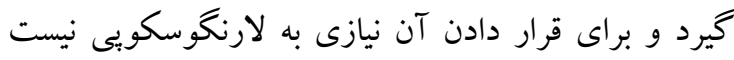

در لوله كذارى تراشه و قرار دادن ماسك حنجره، كشش

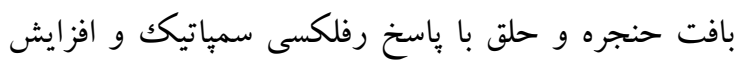

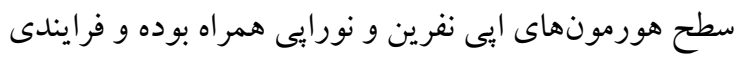
مداخله اى استرسزا محسوب مى شود كه منجر به تغييرات

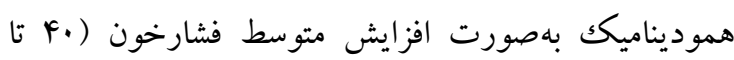
•هدرصد)، افزايش ضربان قلب (·r/\%) و آريتمى همراه

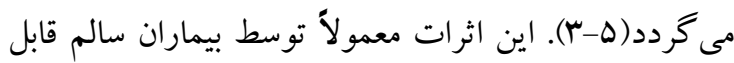
تحمل است اما مىتواند به بيماران مبتلا به بيمارى زمينهاى

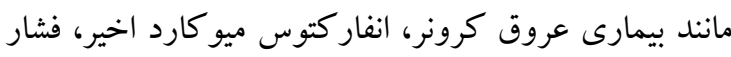
خون بالا، سالمندى و بيمارىهاى مغزى ماند تومور، آنوريسم يا افزايش فشار داخل جمجمه و غيره كشنده بوده

و بيمار رادر معرض خطر بالاى مر گكومير قرار دهد (9). هدف اصلى متخصص بيهوشى تضعيف باسخ هاى اتونوميك و هموديناميك به محر كك هاى مضر، ضمن حفظ هن

$$
\text { عملكرد كافى گردش خون است (V) }
$$
طيف وسيعى از عوامل القاكننده بيهوشى ماند اتوميديت،

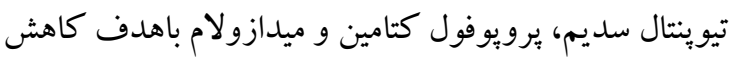

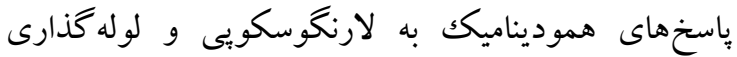




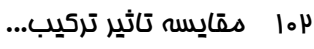

راه هوايى با ETT و LMA تقسيم شدند. در اين مطالعه بيماران از روش حفظ راه هوايى حين بيهوشى اطلاعى

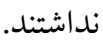

كليه بيماران در بدو ورود به اتاق عمل تحت مانيتورينگك

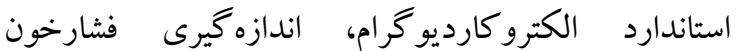
غيرتهاجمى، پِالساكسىمترى و كاينو گرافى قرار گرفتند؛ متغيرهاى هموديناميك شامل تعداد ضربان قلب، فشار متوسط شريانى و اشباع اكسيرن خون محيطى بهعنوان مقادير

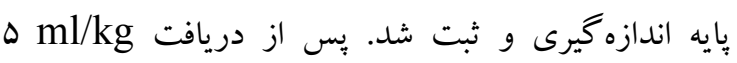

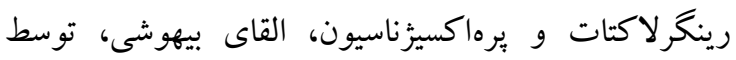

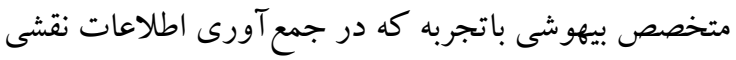

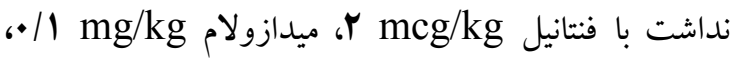
تيوينتال سديم با از دست رفلكس پيلكى وشلى فكك براى تسهيل اداره راه

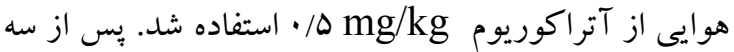

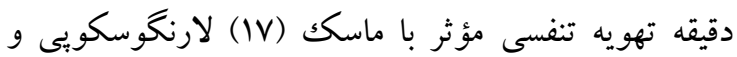

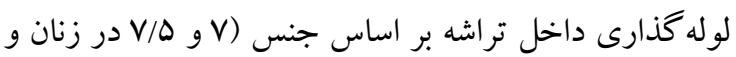

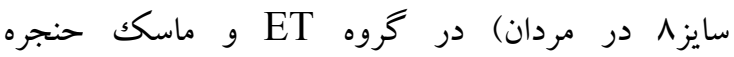

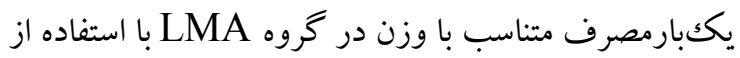
روش كلاسيك قرار داده شد. بِ از تائيد مناسب بودن مكان براى ETT يا LMA و فيكس آن در محل مناسب، بيماران تحت تهويه با فشار مثبت قرار گرفتند. نخهدارى

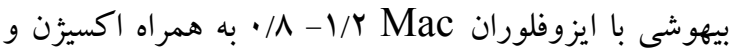

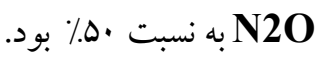
در زمانهاى او بـ دقيقه بعد از القاى بيهوشى و ل، س، هو

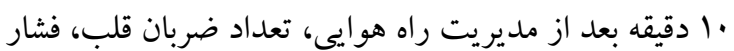
متوسط شريانى (MAP) و درصد اشباع اكسيزن خون

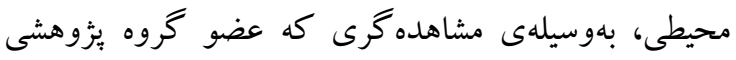

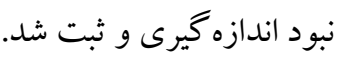

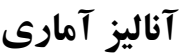

حجم نمونه اين مطالعه توسط فرمول برآورد حجم نمونه

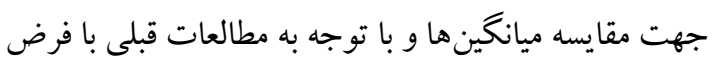

تغييرات هموديناميك در دو روش لوله گذارى داخل تراشه و استفاده از ماسك حنجرهاى با يكديخر مقايسه كنيم.

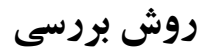
اين مطالعه كارآزمايى بالينى تصادفى يكك سو كور تصادفى

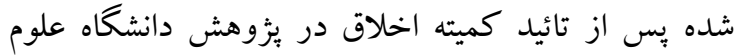
يزشكى اصفهان (IR.MUI.MED.REC.1397.182)

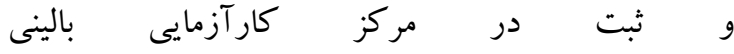
(IRCT20180416039326N6) بر روى · ل بيمار (IR) كانديد جراحى الكتيو تحت بيهوشى عمومى در بيمارستان دانشگاهى فيض در سال Vqrا انجام گرفت. معيار هاى ورود به مطالعه شامل:

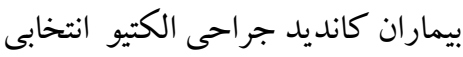
سن هr تا هV سال با ASA يكك و دو

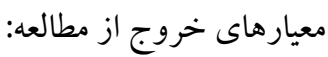
بيشبينى مديريت راه هوايى دشوار بيماران جاق، حامله، ديابتى، بيمارى انسدادى مزمن ريه

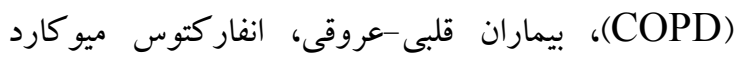
قبلى، بيمارى كليوى، نارسايى عروق مغزى

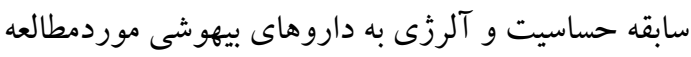
بيش از يككبار تلاش براى لوله كذارى تراشه يا قرار دادن

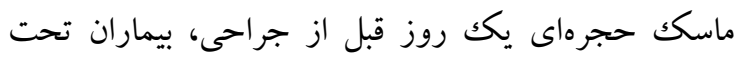
بررسى كامل بيهوشى بخصوص ازنظر سابقه فشارخون بالا، ديابت، درد قفسه سينه، بيمارىهاى انسدادى ريه، تشنج، خسخس سينه و انفار كتوس ميو كارد و نيز سابقه بيهوشى

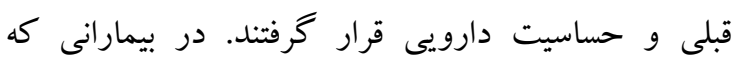
معيارهاى ورود به مطالعه را داشتند. رضايت آكاهانه كرفته و

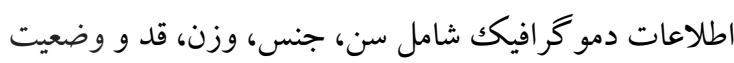
فيزيكى بر اساس طبقه بندى انجمن متخصصين بيهوشى

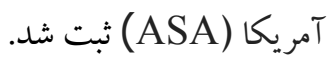

با استفاده از Random Allocation software، بيماران در دو گروه مساوى ها نفره براى بررسى تأثير تركيب تيوينتال سديم-ميدازولام بر باسخ استرسى به اداره 


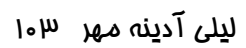

آزمون repeated test ANOVA استفاده شد.

يافته ها

در اين مطالعه بَأ بيمار كانديد جراحى الكتيو با بيهوشى عمومى در روز قبل از عمل مورد ارزيابى بيهوشى قرار كرفتد بر اساس معيارهاى ورود به مطالعه ·V بيمار واجد

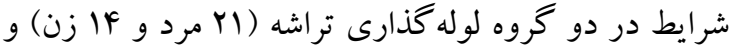
قرار دادن ماسك حنجره (19 مرد و 19 زن) وارد مطالعه شدند (شكل () بين دو گروه اختلاف معنىدارى بر اساس

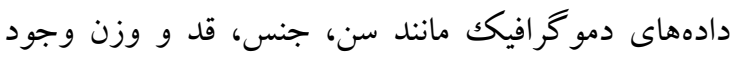

$$
\text { نداشت (ه•/P> (P) (جدول (). }
$$

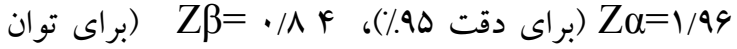

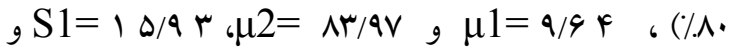

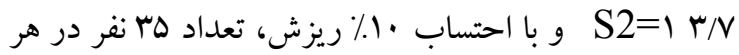
كروه يا •V بيمار در دو گروه به دست آمد.(rا) اطلاعات

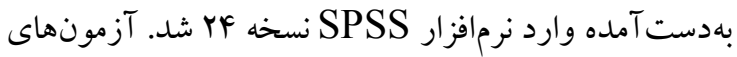

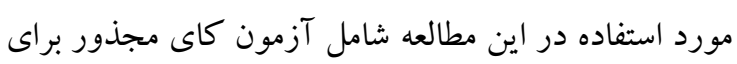

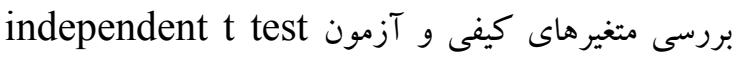

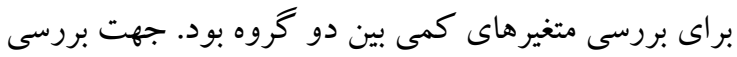

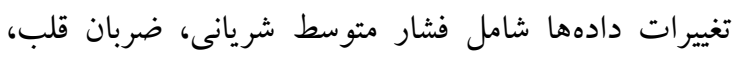
درصد اشباع اكسيزّن شريانى، در زمانهاى مختلف از منسي

جدول ا: متغيرهاى دمو كرافيك بيماران مورد مطالعه در دو كروه

\begin{tabular}{|c|c|c|c|c|}
\hline P-value & كروه ماسك حنجرهاى & گروه لوله گذارى داخل تراشه & \multicolumn{2}{|c|}{ متغير | لمتر } \\
\hline. .09 & $\Delta F / \Delta q \pm q r / I V$ & $91 / \Delta \cdot \pm 9 / 11$ & & سن (سال) \\
\hline \multirow[t]{2}{*}{$r \%$} & $19(\% / F \Delta)$ & YI(\%.4.) & مرد & جنس | جن \\
\hline & $19(\% / \Delta F)$ & $1 F\left(\% \%_{*}\right)$ & زن & \\
\hline $1 \%$ & $V \psi / \backslash 94 \pm \Delta q / V$ & $\Lambda \cdot / 19 \mathrm{~V} \pm 9 \% / q$ & \multicolumn{2}{|c|}{ قد (cm) } \\
\hline $.9 /$. & $|q / 9 \vee \pm \wedge 9 /|$. & $9 \mathrm{~V} / 99 \pm r \mathrm{r} / / \mathrm{F}$ & \multicolumn{2}{|c|}{ وزن (kg) } \\
\hline
\end{tabular}




\section{ثُبت نام}

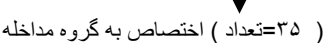

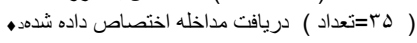

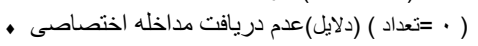

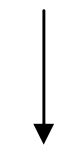

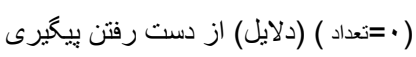

(دتعداد ) (دلايل)توقف مداخله

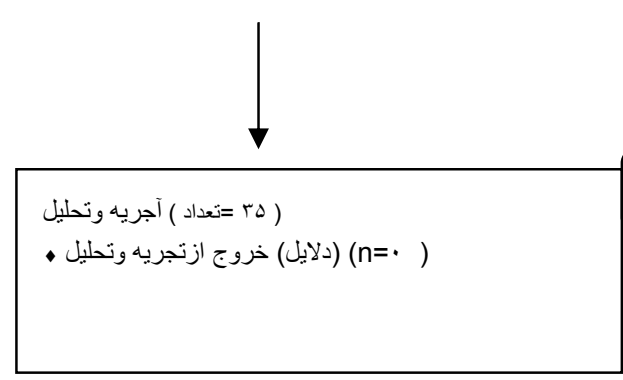

شكل 1: فلوجارت مطالعه

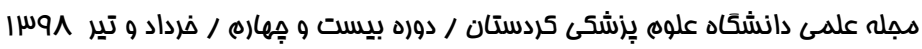




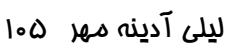

اساس ضربان قلب در زمانهاى ا و r دقيقه بعد از لولهتعداد ضربان قلب، فشار متوسط شريانى و درصد اشباع كذارى وجود داشت بهطورى كه ضربان قلب در اين زمانها اكسيزّن شريانى، در زمانهاى ا و r دقيقه بعد از القاى در گروه لوله گذارى داخل تراشه بهصورت معنىدارى

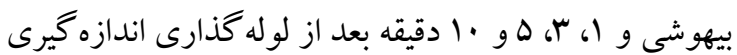
بالاتر از كروه LMA بود (ه./P>•P(جدول Y) تغييرات شد، بين دو گروه اختلاف معنىدارى بر اساس فشار متوسط فشار متوسط شريانى، درصد اشباع اكسيزن شريانى، ضربان شريانى و درصد اشباع اكسيزن شريانى در زمانهاى ا و r قلب، در زمانهاى ذكر شده در گروهها و بهصورت كلى در دقيقه بعد از القاى بيهوشى و ا، آ، هـ و •ا دقيقه بعد از لوله-

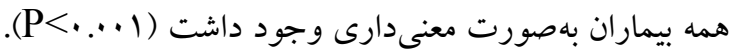
كذارى وجود نداشت (ه>/P> ) همجينين بين دو گروه هيج گونه عوارضى ماند شكستگى دندان، لارنگگ اسباسم و اختلاف معنىدارى بر اساس ضربان قلب در ا دقيقه بعد از سرفه در دو كروه ديده نشد. القاى بيهوشى، ه و ·لا دقيقه بعد از لوله خذارى وجود نداشت (ه> P> P> ). اما بين دو گروه اختلاف معنىدارى بر

جدول Y: متغيرهاى هموديناميك اندازهگيرى شده در بيماران در دو گروه مورد مطالعه

\begin{tabular}{|c|c|c|c|c|}
\hline $\mathrm{P}$ value & كروه ماسك حنجرهاى & كروه لوله كذارى داخل تراشه & زمان & متغير \\
\hline$F F /$. & $\Delta V / 1 \cdot V \pm q 1 / 19$ & $r \cdot / 9 \Delta \pm 1 \Delta / r r$ & ا دقيقه بعد القا & \\
\hline$\mu \mathrm{r} / \cdot$ & $\Delta V / 91 \pm 9 N / / F$ & $\Lambda \Delta / \Lambda \Delta \pm q \cdot / r Y$ & r د دقيقه بعد از القا & \\
\hline $19 /$ & $91 / 9 \Delta \pm \cdot Y / / V$ & $Y N / q \cdot \pm q Y / Y r$ & ا دقيقه بعد از لوله گذار & \\
\hline
\end{tabular}

\begin{tabular}{|c|c|c|c|c|}
\hline $\mathrm{IV} / \cdot$ & $9 N / 9 Y \pm 9 Q / Y$. & $a r / I V \pm r 4 / \Lambda 18$ & بـ دقيقه بعد از لوله كذارى داخل تراشه & متوسط فشارشريانى \\
\hline $\mathrm{VV} / \cdot$ & $\Delta \cdot / 1 \xi \pm V / / \Lambda \Delta 8$ & $Q V / V \Lambda \pm q V / I V$ & ه دقيقه بعد از لوله كذارى داخل تراشه & \\
\hline ११/• & $.9 / \mathrm{Ar} \pm 19 / 1 \mathrm{~F}$ & $99 / 11 \pm 9 Y / 11$ & •ا دقيقه بعد از لوله كذارى داخل تراشه & \\
\hline $\mathrm{rV} / \cdot$ & $F Y / q q \pm q V / 1$ & $\cdot \Delta / 9 \vee \pm \wedge 9 / 1$ & ا دقيقه بعد القا & \\
\hline $\mathrm{rl}_{\mathrm{l}}$. & $\cdot \Delta / q \wedge \pm q \cdot / 1$ & $\Lambda r / q \Lambda \pm \cdot \vee / 1$ & r د دقيقه بعد از القا & \\
\hline $\mathrm{kr} / \mathrm{.}$ & $\Delta \mathrm{V} / q \Lambda \pm q \mathrm{~V} / \cdot$ & $\wedge \Delta / ৭ \wedge \pm 11 / 1$ & ادقيقه بعد از لوله كذارى داخل تراشه & \\
\hline $94 /$. & $\psi \cdot / 9 \Lambda \pm r \mid / 1$ & $91 / 91 \pm .9 / 1$ & لم دقيقه بعد از لوله كذارى داخل تراشه & \\
\hline$\Lambda \cdot / \cdot$ & $9 Y / 9 \wedge \pm \cdot 1 / 1$ & $9 \Delta / 9 \Lambda \pm 9 r /$. & هـ دقيقه بعد از لوله كذارى داخل تراشه & اشباع اكسيزن شريانى \\
\hline$\wedge \mathrm{V} / \cdot$ & $r F / Q \Lambda \pm r Y / l$ & $M N / 9 \wedge \pm I V / I$ & • ادقيقه بعد از لوله گذارى داخل تراشه. & \\
\hline $11 \%$ & $r \Lambda / V A \pm r \Delta / / r$ & $Q F / V \Lambda \pm I V / I V$ & ا دقيقه بعد القا & \\
\hline$r / \cdot$ & $.1 / V \Delta \pm r r / 1$. & $\Delta 1 / V 9 \pm 10 / 10$ & 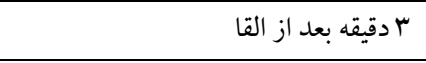 & \\
\hline$\cdots 1 /$ & $Y \Lambda / V F \pm 1 \cdot / 1$ & $9 F / V V \pm 1 \cdot / 19$ & ا دقيقه بعد از لوله كذارى داخل تراشه & \\
\hline$. \mu /$. & $\Lambda Y / V \cdot \pm \cdot V / I r$ & $\cdot \Lambda / V F \pm \Lambda \cdot / / F$ & بـ دقيقه بعد از لوله كذارى داخل تراشه & ضربان قلب \\
\hline $11 / \cdot$ & $9 F / 94 \pm \cdot \Delta / 11$ & $r r / V \cdot \pm I r / I r$ & ه دقيقه بعد از لوله كذارى داخل تراشه & \\
\hline $\mid r / \cdot$ & $99 / 9 \uparrow \pm \cdot N / 1$. & $9 V / 99 \pm .9 / 1 Y$ & •ادقيقه بعد از لوله كذارى داخل تراشه. & \\
\hline
\end{tabular}


1.4 مقايسم تاثير تركيب...

\begin{tabular}{|c|c|c|c|c|}
\hline$V F /$. & $V I / I F r \pm \Delta I / Y \Delta$ & $G Y / I Y \Delta \pm \Delta F / Y G$ & ا دقيقه بعد القا & \\
\hline $1 . \%$ & $\Delta F /|r| \pm Y r / Y I$ & $91 / 1 / 9 \pm \Delta \Delta / r Y$ & r دقيقه بعد از القا & \\
\hline $9 Y / \cdot$ & $\cdot \Lambda / I Y V \pm F \Lambda / Y r$ & FN/IYYE.V/YF & ادقيقه بعد از لوله گذارى داخل تراشه & \\
\hline $19 /$. & $M /|Y| \pm V Y / Y Y$ & $\vee / / 19 \pm \Delta \Delta / I V$ & r r دقيقه بعد از لوله كذارى داخل تراشه & فشارخون سيستولى (ميليمتر جيوه) \\
\hline$f \cdot / \cdot$ & $r M / l f \pm V V / r$. & $F \wedge / 11 \cdot \pm 91 / 1 \wedge$ & ه دقيقه بعد از لوله كذارى داخل تراشه & \\
\hline $1 N / \cdot$ & $V \Delta / \backslash \| \pm q F / \backslash \Lambda$ & $V \cdot /\| \pm F\| / / F$ & • ادقيقه بعد از لوله كذارى داخل تراشه & \\
\hline$\cdot \mathrm{V} / \cdot$ & $r \mid / \Lambda F \pm F \Delta / 11$ & $\Delta I / A \cdot \pm r r / I V$ & 1 ادقيقه بعد القا & \\
\hline$r Y / \cdot$ & $9 F / V G \pm F \mid / 11$ & $G Y / V Y \pm \wedge 9 / 19$ & r دقيقه بعد از القا & \\
\hline$\wedge \Lambda / \cdot$ & $r \wedge / \Lambda I \pm \Delta q / \backslash F$ & $11 / \mathrm{N} \pm \mathrm{r} \Delta / 1 \Delta$ & ا دقيقه بعد از لوله كذارى داخل تراشه & \\
\hline $.9 / \cdot$ & $V F / V V \pm \Delta \cdot / 19$ & $r \Delta / V Y \pm \Delta r / I r$ & بـ دقيقه بعد از لوله كذارى داخل تراشه & فشارخون دياستولى (ميليمتر جيوه) \\
\hline $91 /$. & $\Lambda \Delta / V \backslash \pm \cdot F / \backslash F$ & $r N / V \cdot \pm 91 / 1 r$ & ه دقيقه بعد از لوله كذارى داخل تراشه & \\
\hline$\wedge 9 /$. & $৭ 9 / V \cdot \pm \Delta 1 / 1 r$ & $F V / V r \pm F \Delta / I r$ & • ادقيقه بعد از لوله كذارى داخل تراشه & \\
\hline
\end{tabular}

نتايج مطالعه ما نشان داد تركيب تيوينتال -ميدازولام با

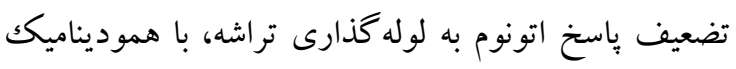

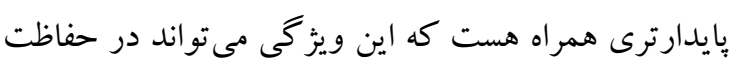
از بيماران با ريسك بالاى بيمارى هاى قلبى عروقى قابل تأمل هدف از اين مطالعه بررسى تأثير تركيب تيوينتال سديم-

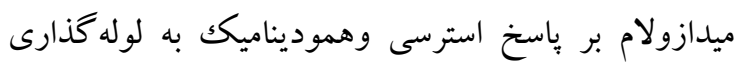
تراشه و قراردادن ماسك حنجره بود.

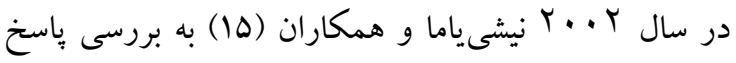
هموديناميكك به القاى بيهوشى با تركيب تيوينتال-ميدازولام در مقايسه با تيوينتال بهتنهايى يرداختند.القاء بيهوشى در

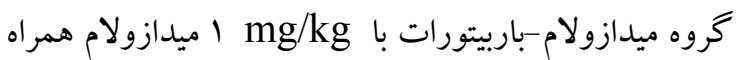

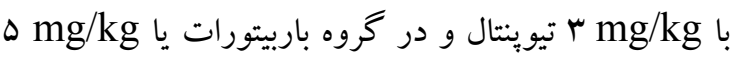
تيوينتال انجام شد در هر دو گروه، لوله گذارى تراشه با بال افزايش فشارخون و ضربان قلب همراه بود كه اين باسخ در كروه تيو ينتال بارزتربود.و نتيجه گرفتندكه تركيب تيوينتالميدازولام در مقايسه با تيوينتال ، بهطور مؤثرى باسخ سيستم

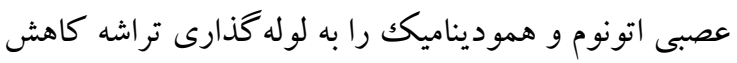

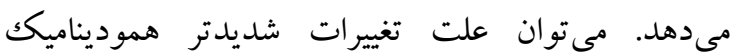

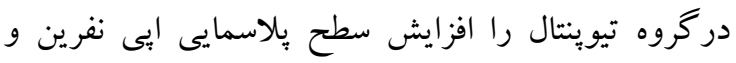

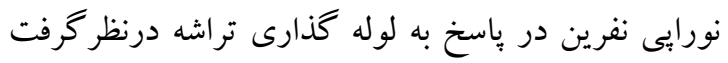

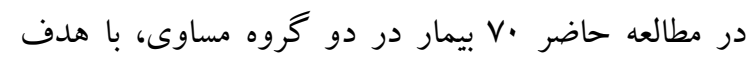

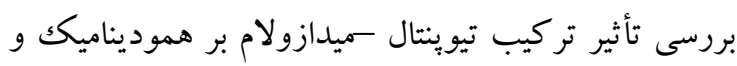

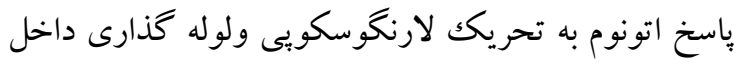
تراشه و واردكردن ماسكك حنجره موردمطالعه قرار گرفتند. بيماران در دو گروه ازنظر مشخصات دمو گرافيك شامل ونال سن، جنس، كلاس ASA، وزن و يارامترهاى هموديناميك دون

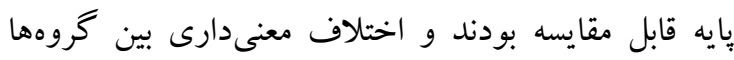
مشاهده نشد. در نتايج به دست آمده بين دو گروه ETT و

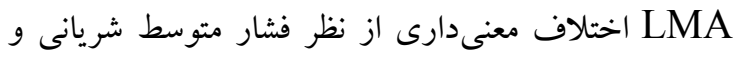

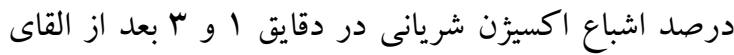

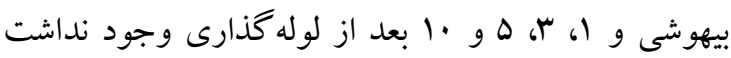

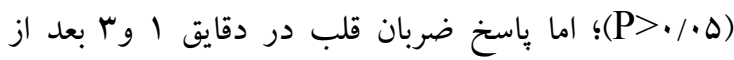
لوله كذارى تراشه بهصورت معنىدارى بيش از قرار دادن ماسك حنجره بود (Y (1) (1). 
ليلى آدينم همر loV

سطح بايه همراه بود و ميزان ضربان قلب در گروه B و C

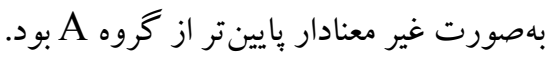

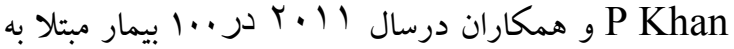
فشارخون بالا به مقايسه تغييرات ضربان قلب و فشارخون دياستوليك به دنبال القاى بيهوشى با تركيب تيوينتال -

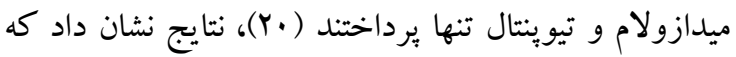
نايايدارى ضربان قلب و فشارخون دياستوليك در كروه

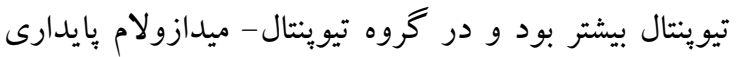

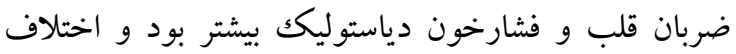
معنى دارى بين دو گروه وجود داشت در مطالعه فوق عليرغم كاهش •ه درصدى در دوز القاء بيهوشى تيوينتال سديم

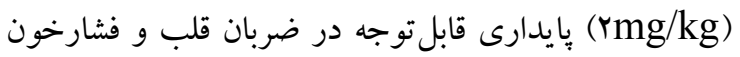
دياستوليك وجود داشت. دليل آن مىتواند وجود نايايدارى نياري هموديناميك در بيماران با فشارخون بالا و حساسيت بيشتر دون

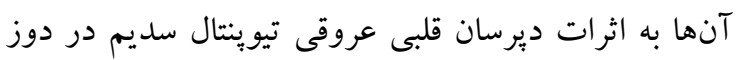

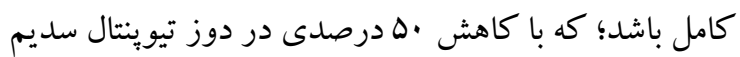
و تجويز هم زمان ميدازولام بايدارى هموديناميك فراهم

شد

Kishnani قراردادن ماسك حنجره Proseal ولوله گذارى تراشه در القاء بيهوشى بإيرويوفول را بررسى كرد. و در نتيجه گيرى مطالعه اعلام كرد كه عليرغم خصوصيات ايمنى قابلمقايسه در دو روش اداره راه هوايى، ياسخ هموديناميكك به قرار دادن ماسك حنجره به ميزان قابل توجهى كمتر از

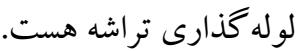
رحمان و همكاران در مطالعهاى •10 بيمار را بهصورت تصادفى به سه گروه موردمطالعه قرارداد (YY). در گروه اول

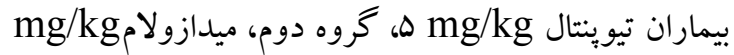

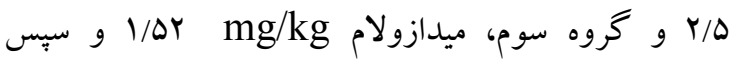
تيويتتال r/ه mg/kg تزريق شد و براى تسهيل لوله كارى تراشه ازساكسينيل كولين (Suxamethonium) استفاده

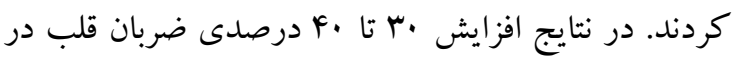

LLahsaee تحت القاء بيهوشى با تيوينتال (گروه ()، يرويوفول (كروه Y) و تركيب تيوينتال و يرويوفول در دوز بايين (كروه ؟) قراردادند (1)). بِ إز القاء بيهوشى همه بيماران، افت

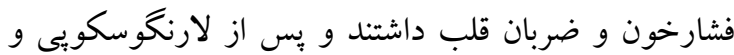
لوله گذارى داخل تراشه، افزايش فشارخون و ضربان قلب داشتند در بيماران گروه ب ميزان كاهش فشارخون و ضربان قلب ازكمتراز گروه يرويوفول و ميزان افزايش فشارخون و

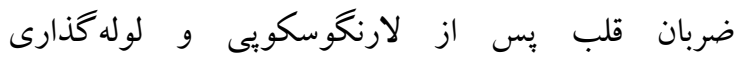

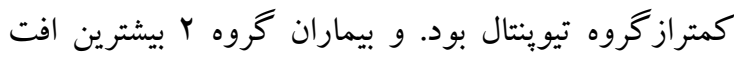

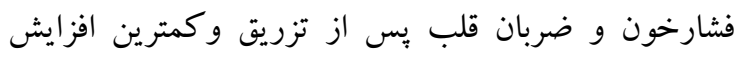

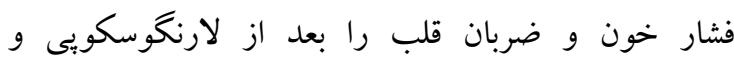

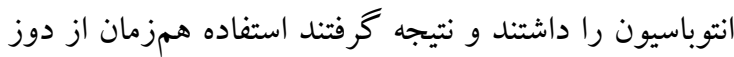
بايين تيوينتال و برويوفول براى القاى بيهوشى باعث كاهش

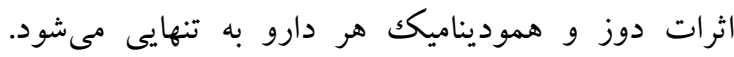
استفاده تركيبى از دوز كم اين داروها باعث كاهش تغييرات

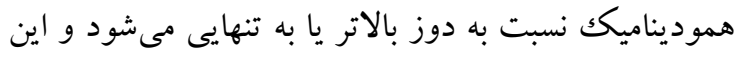
موضوع را در بيماران مسن و مبتلايان به بيمارىهاى قلبى و فشار خون حائز اهميت دانستند

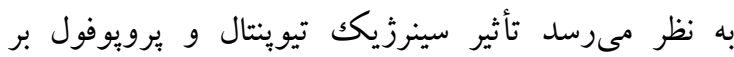

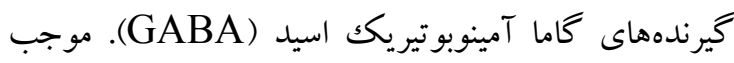
تضعيف پاسخ اتونوم به تحريك راه هوايى و كاهش تغييرات هموديناميك در گروه ب شده است Khan MA 9 بيمار مبتلا به فشارخون بالا با كلاس ASA اوץ را به سه

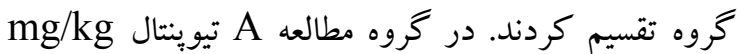
F نرمال سالين Ml r داده شد. در گروه B، تيوينتال

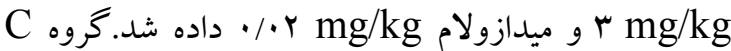
تيوينتال mg/kg r و ميدازولام mg/kg r ×.• را دريافت كرد در گروههاى B و C (كروههاى القاءهمزمان) در مقايسه با گروه A (تيوينتال) فشارخون سيستوليك و و

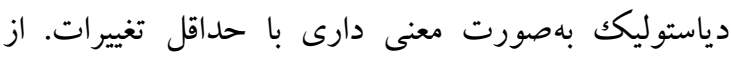




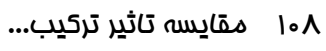

\section{نتيجه تيرى}

اما مطالعه ما نشان مىدهد القاى بيهوشى با تركيب تيوينتال

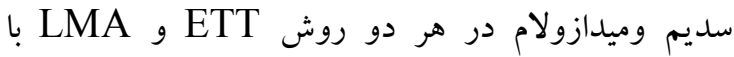
تضعيف باسخ استرسى و تغييرات جزئى و مشابه بر متغير هاى هموديناميك همراه بوده و روشى مؤثر و ايمن براى القاء

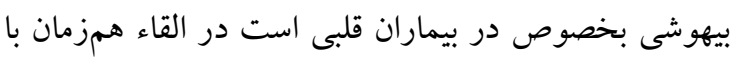

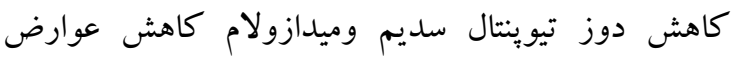
هريكك از آنها را خواهيم داشت. تيو ينتال سديم وميدازولام

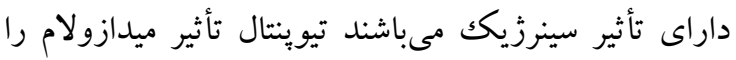
تقويت مى كند و ميدازولام تيوينتال را تقويت مى كنند بنابراين مىتوان جهت القاى بيهوشى از تركيب تيوينتال سديم r/ه mg/kg و ميدازولام لوله كذارى داخل تراشه و قراردادن ماسك حنج حلدره استفاده

از محدوديتهاى مطالعه حاضرمى توان به تكك مركز بودن

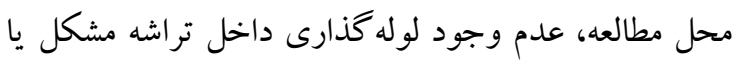

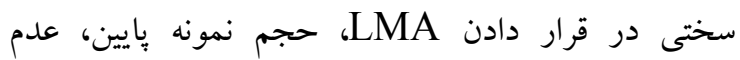

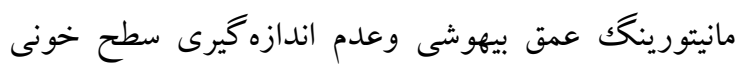
كاتكو لامين ها اشاره كرد.

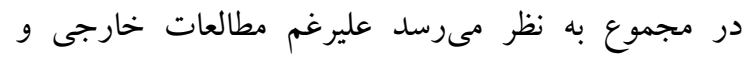

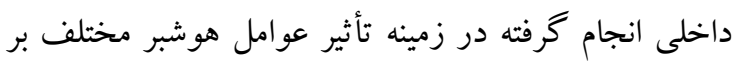

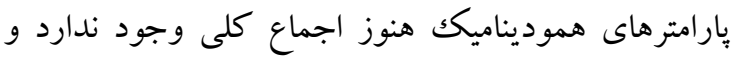
نياز به انجام مطالعات بيشتر ضرورى است.

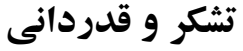

مقاله حاضر، حاصل باياننامه دكتراى حرفهاى در رشته

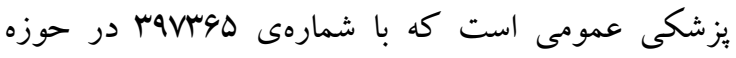

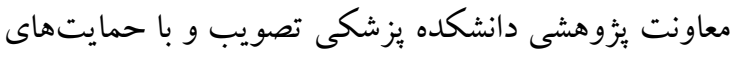
اين معاونت انجام شده است. از اينرو، نويسند كان مقاله از زحمات ايشان تشكر و قدردانى مىنمايند.

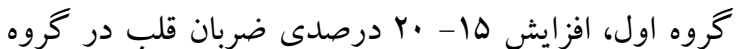
دوم و سوم وجود داشت. و با افت قابل توجه فشار خون سيستوليك و دياستوليك در پايان r دقيقه همراه بود در

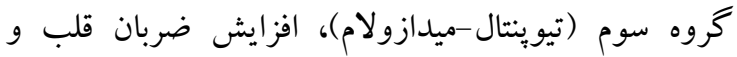
كاهش فشارخون حداقل بود. محققين درنتيجه گيرى خود اعلام كردند القاء همزمان بيهوشى با ميدازولام تيوينتال

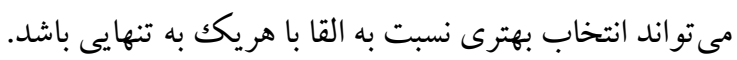

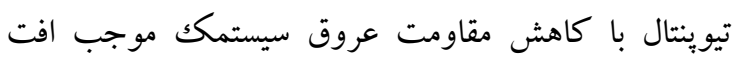
فشارخون و افزايش جبرانى ضربان قلب مىشود اين باسخ

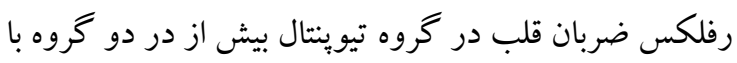
القاء بيهوشى تر كيبى بوده است. در مطالعه حاضر تأثير القاى بيهوشى با تركيب تيوينتال -

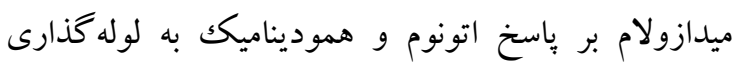

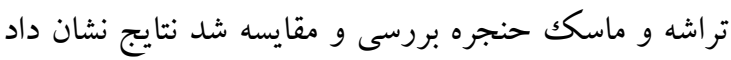

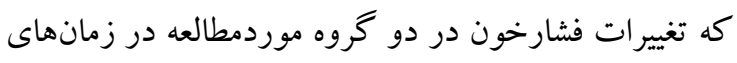

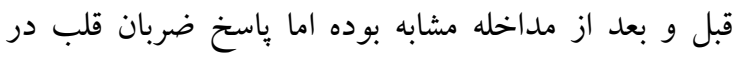

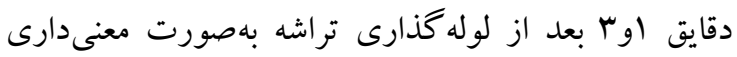

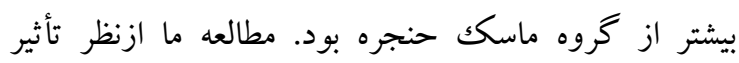
تركيب تيوينتال- ميدازولام بر تغييرات هموديناميكك و ونجره

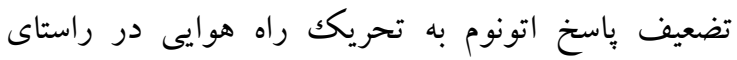

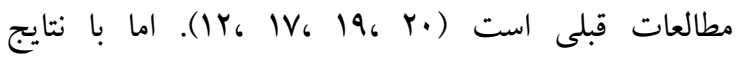
مطالعه Kishnani در سال 19 r همسويى كامل نداشت تفاوت رامى توان در نوع عامل هوشبر و ت تاثيرآن برهموديناميك و باسخ اتونوم به تحريك راه هوراه

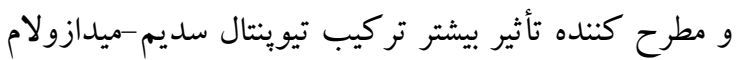

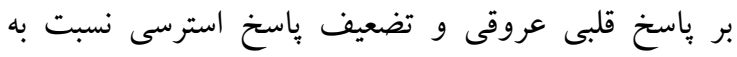
يرويوفول است.

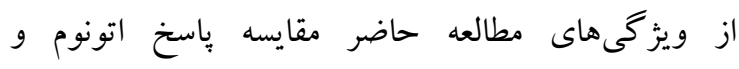
هموديناميك در دو روش اداره راه هوايى است. لارنخوسگويى ولوله كذارى تراشه با استرس و وباسخ هموديناميك بيشترى نسبت به كار گذارى ماسك حنجره

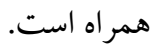




\section{References}

1. Aitkenhead AR, Rowbotham DJ, Smith G. Text book of Anaesthesia. 4th ed. Churchill Livingstone, 2001:101-6, 423-514.

2. Edward Morgan G. Mikhail MS, Murray MJ. Clinical Anaesthesiology. 4th ed. Lange Medical Books; McGrawn-Hill Medical Publishing Division, 2008: 97-110.

3. Sulaiman S, Karthekeyan RB, Vakamudi M, Sundar AS, Ravullapalli H, Gandham R. The effects of dexmedetomidine on attenuation of stress response to endotracheal intubation in patients undergoing elective off-pump coronary artery bypass grafting. Ann Card Anaesth 2012;15:39-43.

4. Menda F, Köner O, Sayin M, Türe H, Imer P, Aykaç B. Dexmedetomidine as an adjunct to anesthetic induction to attenuate hemodynamic response to endotracheal intubation in patients undergoing fast-track CABG. Ann Card Anaesth 2010;13:16-21.

5. Safavi M, Honarmand A, Azari N. Attenuation of the pressor response to tracheal intubation in severe preeclampsia: relative efficacies of nitroglycerin infusion, sublingual nifedipene, and intravenous hydralazine. Anesth Pain 2011;1:81-9.

6. Pegu B, Dutta S, Pathak DG, Deori KC. Attenuation of stress response to laryngoscopy and intubation: sublingual nitroglycerin spray vs intravenous fentanyl and sublingual nitroglycerin spray. Int J Basic Clin Pharmacol 2017; 6:1414.

7. Das A, Saha TK, Majumdar S, Mandal RD, Mukherjee A, Mandal SK. Comparative evaluation of oral clonidine and midazolam as premedication on preoperative sedation and laryngoscopic stress response attenuation for the patients undergoing general anaesthesia. Int $\mathbf{J}$ Med Public Health 2013;3:200-6.

8. Habibi MR, Baradari AG, Soleimani A, Zeydi AE, Nia HS, Habibi A, et al. Hemodynamic responses to etomidate versus ketamine-thiopental sodium combination for anesthetic induction in coronary artery bypass graft surgery patients with low ejection fraction: a doubleblind, randomized, clinical trial. J Clin Diagn Res 2014;8:GC01-5.

9. Kord Valeshabad A1, Nabavian O2, Nourijelyani K3, Kord H4, Vafainejad H2, Kord Valeshabad R5, et al. Attenuation of Hemodynamic Responses to Laryngoscopy and Tracheal Intubation: Propacetamol versus Lidocaine-A Randomized Clinical Trial. Anesthesiol Res Pract 2014;2014:170247.

10. Abbasivash R, Aghdashi MM, Sinaei B, Kheradmand F. The effects of propofolmidazolam-ketamine co-induction on hemodynamic changes and catecholamine response. $\mathrm{J}$ Clin Anesth 2014;26:628-33.

11. Meftahuzzaman SM, Islam MM, Ireen ST, Islam MR, Kabir H, Rashid H, et al. Comparison of efficacy of labetalol and fentanyl for attenuating reflex responses to laryngoscopy and intubation. MMJ 2014;23:242-8.

12. Smischney NJ1, Beach ML, Loftus RW, Dodds TM, Koff MD. Ketamine/propofol admixture (ketofol) is associated with improved hemodynamics as an induction agent: a randomized, controlled trial. J Trauma Acute Care Surg 2012;73:94-101. 
.....

13. Reves JG, Glass PS, Lubarsky DA, McEvoy MD, Martinez-Ruiz R. Intravenous anesthetics. In: Miller RD, Eriksson LI, Fleisher L, Wiener-Kronish JP, Young WL, editors. Miller's Anesthesia. 7th ed. Philadelphia: Elsevier Churchill Livingstone, 2010:719-68.

14. Goel S, Bhardwaj N, Jain K. Efficacy of ketamine and midazolam as coinduction agents with propofol for laryngeal mask insertion in children. Paediatr Anaesth 2008;18:628-34.

15. Nishiyama T, Misawa K, Yokoyama T, Hanaoka K. Effects of combining midazolam and barbiturate on the response to tracheal intubation: changes in autonomic nervous system. $\mathrm{J}$ Clin Anesth 2002;14:344-8.

16. Saghei M, Shetabi H, Golparvar M, predicting efficacy of post induction mask ventilation based on demographic and anatomical factors. Adv Biomed Res 2012;1:10.

17. Manne GR, Upadhyay MR, Swadia V. Effects of low dose dexmedetomidine infusion on haemodynamic stress response, sedation and post-operative analgesia requirement in patients undergoing laparoscopic cholecystectomy. Indian J Anaesth 2014;58:726-31.

18. Lahsaee M, Kamalipour H, Ajeli Z, Kamali K. A comparison of hemodynamic changes during laryngoscopy and endotracheal intubation by using three modalities of anesthesia induction. APICARE 2012;16:247-51.

19. Khan MA, Khan FA. Midazolam and thiopentone co-induction: Looking for improvement in quality of Anaesthesia. J Pak Med Assoc 2003;53:542-7.

20. Khan P, Zeb A, Rasool G. Comparative study of co-induction with thlopentone and midazolam versus thlopentone alone in hypertensive patients. JPMI 2007;21:966-9.

21. Kishnani PP, Tripathi D, Trivedi L, Shah K, Patel J, Ladumor J. Hemodynamic stress response during insertion of proseal laryngeal mask airway and endotracheal tube-a prospective randomized comparative study. Int J Res Med 2016;5:34-8.

22. Rahman $\mathrm{MH}$, Hassan M, Monirul Islam MM. Midazolam and thiopentone as coinduction. J BSA 2004;17:23-7. 